\title{
Métodos e estratégias em proteômica e suas aplicações na área vegetal
}

\author{
Methods and strategies in proteomics and their applications in plants
}

\author{
Fernanda Salvato ${ }^{\mathrm{I}}$ Mayra Costa da Cruz Gallo de Carvalho"
}

\section{-REVISÃO BIBLIOGRÁFICA-}

RESUMO

A implementação da espectrometria de massa (MS) para as análises de peptídeos (MS) e de aminoácidos (MS em tandem ou MS/MS) tornou possível a identificação de centenas de proteínas em experimentos únicos. Uma grande variedade de estratégias está disponível atualmente para o fracionamento e a purificação de amostras, a identificação de proteínas, a quantificação, a análise de modificações póstraducionais (MPT's) e os estudos de interação. Dessa forma, a proteômica abre novas perspectivas na biologia de plantas com ênfase nos estudos de variabilidade genética, estresses fisiológicos e desenvolvimento de plantas.

Palavras-chave: proteômica, análise de proteínas, interatômica, plantas.

\section{ABSTRACT}

The implementation of mass spectrometry (MS) for peptides (MS) and amino acids (tandem MS or MS/MS) analysis allowed the identification of hundreds of proteins in single experiments. A number of different strategies are current available for sample fractioning and purification, proteins identification, quantification, post-translational modifications (PTM) and interaction analyses. In this way, the proteomics open up new perspectives in plant biology with emphasis on studies of genetic variability, physiological stresses and plant development.

Key words: proteomics, protein analysis, interactomics, plants.

\section{INTRODUÇÃO}

No contexto da genética atual, o fenótipo pode ser observado a partir dos pontos de vista morfológico, fisiológico, bionquímico e molecular. Sob a visão molecular, o fenótipo pode ser descrito em termos de RNAm e proteínas, associados ao genoma e influenciados pelo ambiente. Dessa maneira, a relação entre genótipo e fenótipo torna-se bastante complexa (MATTICK, 2003). A sequência de um gene não deve ser mais considerada isoladamente na predição de sua função, e a análise do RNAm é somente um pouco mais informativa. Já a atividade das proteínas está proximamente associada à função do gene, uma vez que é o produto final da regulação da atividade gênica. Nesse sentido, a proteômica, que visa a caracterizar o conjunto de proteínas expressas em um dado momento, surge como mais uma ramificação entre as ômicas para complementar os estudos sobre a biologia molecular das células (WILKINS et al., 1996). A proteômica é também uma poderosa ferramenta no melhoramento genético, pois, diferentemente do que ocorre quando são utilizados marcadores fenotípicos ou baseados em DNA, a proteômica fornece informação em nível molecular da variabilidade genética que é efetivamente expressa do genoma (PENNINGTON \& DUNN, 2001).

IDepartamento de Genética, Escola Superior de Agricultura Luiz de Queiróz (ESALQ), Universidade São Paulo (USP). Av. Pádua Dias, n.11, CP 9, 13418-900, Piracicaba, SP, Brasil. E-mail: fersalvato@gmail.com. Autor para correspondência.

ID Departamento de Ciências Biológicas, Universidade Estadual Paulista (UNESP), Assis, SP, Brasil. 
Muitas das tecnologias hoje utilizadas na proteômica foram desenvolvidas muito antes do início da "proteômica". No entanto, foi o avanço na tecnologia de sequenciamento de proteínas por meio da espectrometria de massas que possibilitou o seu surgimento e desenvolvimento (TYERS \& MANN, 2003). O início da proteômica foi marcado pela caracterização de perfis proteicos, passando, posteriormente, a focar outros aspectos como a quantificação de proteínas, as interações entre proteínas e as modificações pós-traducionais. Nesta revisão, serão abordadas as principais estratégias para caracterização de proteínas em larga escala e sua aplicação na área vegetal.
Métodos experimentais e tecnologia

O fluxo experimental normalmente utilizado na proteômica consiste na extração de proteínas, separação, quantificação e, por último, na sua identificação (Figura 1). As informações sobre o proteoma de uma amostra podem derivar da análise de proteínas intactas (proteômica top-down) ou de seus peptídeos (proteômica bottom-up). Na proteômica bottom-up, as proteínas de uma mistura são digeridas, e os peptídeos resultantes são analisados por MS. As limitações dessa estratégia podem estar na cobertura incompleta da sequência das proteínas, na perda das MPT's e nas degradações como resultado da digestão proteolítica. Já a análise top-down permite deduzir a

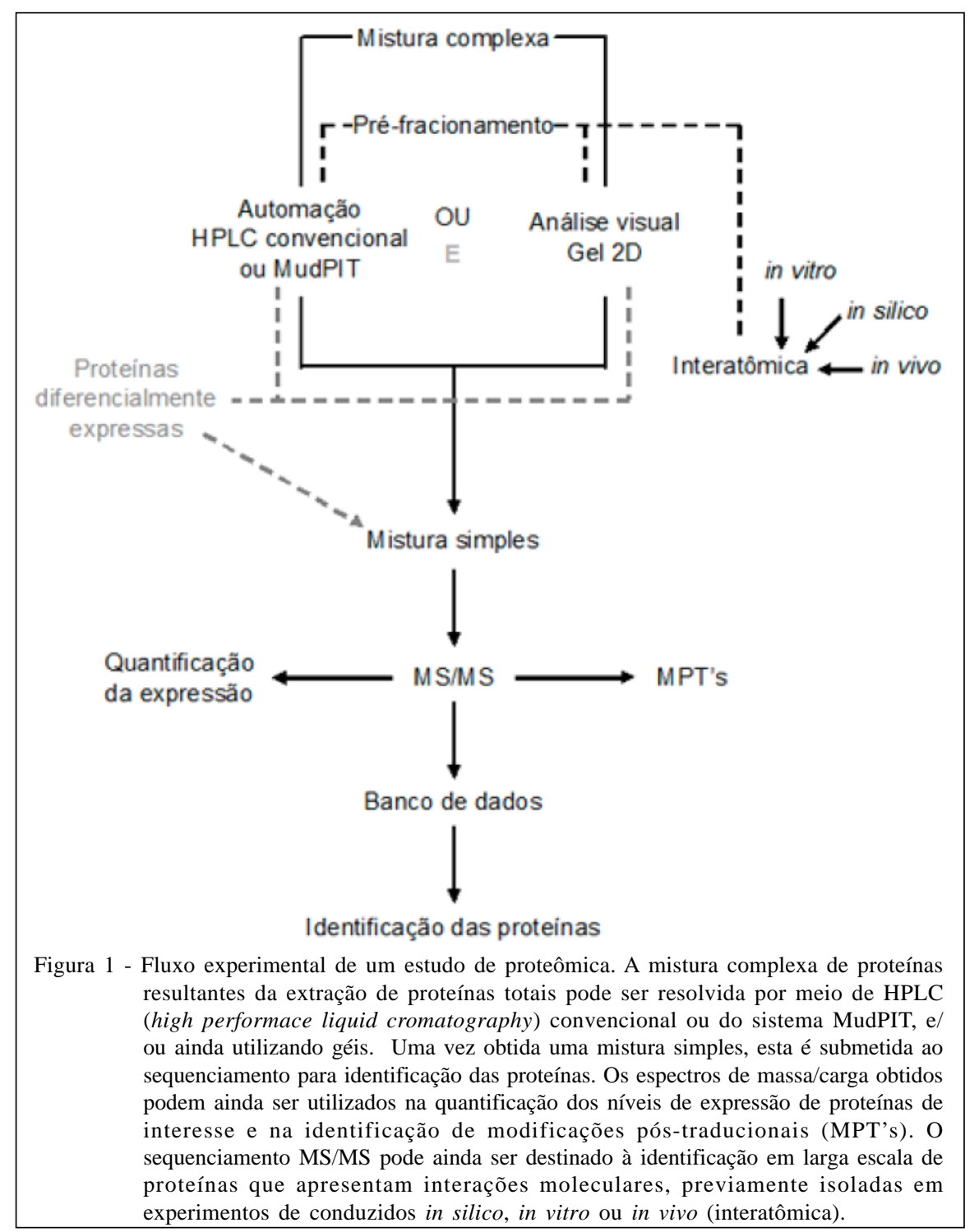

Ciência Rural, v.40, n.3, mar, 2010. 
estrutura primária da proteína e a maior parte das MPT’s. No entanto, essa estratégia é limitada pela energia de colisão necessária na fragmentação da proteína que é insuficiente para proteínas maiores que 50KDa, ficando restrita sua aplicação à análise de proteínas purificadas (NESATY \& SUTER, 2008).

Separação e identificação das proteínas

Após a extração de proteínas, o resultado é uma mistura complexa que deve ser resolvida em frações simples de proteínas individuais ou em uma mistura simples de proteínas para identificação (Figura 1). Na análise bottom-up, de misturas complexas, são utilizados géis desnaturantes (2D) ou cromatrogafia líquida.

Na eletroforese bidimensional a massa e a carga das proteínas são utilizadas em duas etapas (focalização isoelétrica e eletroforese em gel de poliacrilamida) para promover a separação de misturas complexas com melhor resolução. O resultado da eletroforese bidimensional é um perfil de distribuição de spots formados por proteínas únicas ou misturas simples de proteínas (PENNINGTON \& DUNN, 2001). As principais limitações associadas à eletroforese bidimensional são a sua baixa reprodutibilidade e o seu pequeno poder de automação. A reprodutibilidade pode ser aumentada definindo-se condições ótimas para a eletroforese, mas a automação do processo só é possível com relação à análise de géis. Os softwares de análise de géis determinam os spots, identificam aqueles diferencialmente expressos e seus volumes, inferindo uma quantificação relativa da expressão daquela proteína em comparação ao mesmo spot de outro gel (LÓPEZ et al., 2002). Como a automação completa é o principal alvo dos métodos para análises em larga escala, foram desenvolvidos métodos de separação livres de gel por cromatografia líquida de fase reversa acoplada à espectrometria de massas em tandem (LC/ MS/MS). Maior automação é possível com a cromatografia líquida multidimensional que utiliza diferentes características das proteínas em colunas de propriedades distintas ou em uma única coluna bifásica (MOTOYAMA \& YATES, 2008). A fração eluída na primeira coluna é diretamente introduzida na segunda coluna, a qual pode ser diretamente acoplada ao espectrômetro de massas. Essa técnica, chamada de MudPIT (Multidimensional Protein Identification Technology), está inserida no contexto da proteômica shotgun, em que uma maior resolução dos proteomas é possível, facilitando a identificação das proteínas menos abundantes, frequentemente perdidas quando utilizados os géis (WASHBURN et al., 2001).
Depois de separadas as misturas complexas de proteínas, o próximo passo é caracterizar os componentes dessas frações (Figura 1). Quando o objetivo do estudo compreende a produção de mapas proteômicos, a espectrometria de massas surge imperativa, permitindo o processamento de centenas de amostras em uma única análise. A identificação de proteínas por meio da espectrometria de massas depende da digestão proteolítica que produz uma coleção de peptídeos que são ionizados por eletronebulização ou por dessorção a laser auxiliada por matriz (PENNINGTON \& DUNN, 2001). Após a ionização, analisadores de massas detectam as relações massa/carga $(\mathrm{m} / \mathrm{z})$ e os espectros resultantes e relacionam a abundância dos fragmentos versus a relação $\mathrm{m} / \mathrm{z}$, os quais são então confrontados nos bancos de dados para a identificação das proteínas. As análises podem ser realizadas a partir de íons de peptídeos intactos (espectrometria de massa ou MS) fingerprint - ou de peptídeos fragmentados (espectrometria de massa em tandem ou MS/MS) (TWYMAN, 2004). Nas análises de fingerprinting, os valores $\mathrm{m} / \mathrm{z}$ dos peptídeos intactos são correlacionados às proteínas de um banco de dados específico, o que torna esse método aplicável somente às espécies com genomas sequenciados. Já na espectrometria de massas em tandem, a fragmentação dos peptídeos em aminoácidos possibilita determinar a relação $\mathrm{m} / \mathrm{z}$ desses resíduos identificando-se a sequência de aminoácidos, o que torna possível trabalhar com genomas não sequenciados e moléculas desconhecidas (AEBERSOLD\& GOODLETT, 2001).

Análise de modificações pós-traducionais (MPT’s)

Uma das formas de se produzir proteínas diferentes de um mesmo gene é por meio das MPT's. Essas ocorrem em sítios específicos nas proteínas (BLOM et al., 2004), alterando suas propriedades físicas, químicas e biológicas (NESATY \& SUTER, 2008). Elas podem ocorrer por meio de clivagens ou pela adição de um grupo químico a um ou mais aminoácidos (MANN \& JENSEN, 2003). Os principais objetivos dos estudos de MPT’s em proteômica são identificar as proteínas que as apresentam, mapear os sítios onde essas modificações ocorrem, quantificar a ocorrência das MPT's nos diferentes sítios e caracterizar MPT's cooperativas (SEO \& LEE, 2004). Mais de 300 diferentes tipos de MPT's já foram identificados até o momento com o auxílio da espectrometria de massas. $\mathrm{O}$ fato de que modificações covalentes resultam em alterações nas massas moleculares de proteínas torna possível que essas modificações e o aminoácido que as carregam sejam identificados por MS. A espectrometria de 
massas, no entanto, possui um poder reduzido de resolução de MPT's, pois estas ocorrem em níveis estequiométricos baixos (MANN \& JENSEN, 2003). Esse problema pode ser resolvido adotando-se métodos de fracionamento anteriores ao sequenciamento que permitam um enriquecimento da amostra para as proteínas que apresentam um determinado tipo de MPT. Os sistemas de enriquecimento de proteínas modificadas em larga escala são geralmente realizados por meio da cromatografia de afinidade. Um exemplo é o sistema IMAC (coluna de imobilização por afinidade a um metal) para isolamento de proteínas fosforiladas em que íons metálicos de Fe(III) são aderidos à matrix para promover o isolamento de proteínas que possuem resíduos fosforilados, já que o íon Fe(III) é capaz de interagir reversivelmente com o grupo fosfato do peptídeo modificado mantendo-o fixo à coluna (VENER et al., 2001).

Diferentemente do que ocorre com as MPT's reversíveis, nas permanentes, como a glicosilação, a baixa estequiometria não ocorre, mas a adição de carboidratos dificulta a digestão proteolítica necessária para a identificação por MS (PENNINGTON \& DUNN, 2001). Além disso, quando o peptídeo modificado é fragmentado para o sequenciamento, ele perde resíduos de açúcar, impedindo a identificação dos aminoácidos modificados. Para resolver esse problema, realiza-se uma digestão das proteínas de forma a remover os resíduos de açúcar e produzir uma modificação no sítio modificado que o torne identificável (CANTIN \& YATES, 2004).

Géis de eletroforese também podem ser utilizados no enriquecimento de amostras para MPT's como realizado para detecção de fosforilações e glicosilações com kits comercialmente disponíveis. As proteínas modificadas, especificamente marcadas no gel, são visualizadas e excisadas para identificação por espectrometria de massas. Um aspecto interessante do uso de géis para identificação de MPT é a possibilidade de visualizar os spots diferencialmente expressos entre amostras que apresentam a MPT.

\section{Quantificação relativa de proteínas}

Os métodos de quantificação de proteínas em larga escala possibilitam uma estimativa da expressão relativa de proteínas por meio da marcação com isótopos radioativos, fluorescentes e leves/ pesados, permitindo que uma mesma proteína seja quantificada de forma relativa entre amostras marcadas diferentemente. Os mais utilizados são o iCAT (Isotopic coded affinity tag), iTRAQ (isobaric tags) e $\mathrm{H}_{2} \mathrm{O}^{18}$.

$\mathrm{O}$ iCAT consite na adição de uma etiqueta que tem afinidade por resíduos de cisteína e que possui uma molécula ligada de oito átomos de hidrogênio ou oito átomos de deutério. Uma amostra é marcada com a etiqueta contendo hidrogênio e a outra amostra com a etiqueta contendo o deutério. Após digestão das proteínas, os peptídeos resultantes são identificados por MS. Peptídeos iguais marcados nas duas amostras são identificados pela sobreposição dos picos que apresentaram $\mathrm{m} / \mathrm{z}$ distintas devido ao tipo de isótopo ligado, sendo a relação entre a área dos dois picos uma medida relativa da expressão daquela proteína. Os principais problemas associados à técnica são a obrigatoriedade da presença de resíduos de cisteína, o alto custo dos reagentes e o maior tempo necessário para o sequenciamento (YI \& GOODLETT, 2003).

Na técnica de iTRAQ, também é utilizada a marcação de proteínas com etiquetas e identificação por MS. As etiquetas se ligam a todos grupos do tipo amino livres no terminal $\mathrm{N}$ de todos peptídeos e nas cadeias laterais internas com resíduos de lisina e variam em função do grupo repórter que carregam, podendo ter: 114, 115, 116 ou 117Da, possibilitando assim a quantificação de proteínas em até quatro tipos de amostras ao mesmo tempo. A quantificação relativa é realizada da mesma forma que no iCAT, mas seu elevado custo tem restringido seu uso ( SCHMIDT \& URLAUB, 2009).

As técnicas citadas anteriormente requerem o consumo de reagentes específicos e caros. No entanto, o mesmo objetivo pode ser alcançado com um método mais simples de marcação, em que as proteínas são marcadas com um ou dois átomos de $\mathrm{O}$ incorporados no terminal carboxil, por meio do simples fornecimento de uma solução com $\mathrm{H}_{2} \mathrm{O}$ para uma amostra e uma solução com $\mathrm{H}_{2} \mathrm{O}^{18}$ para a outra amostra. Assim, estima-se a abundância relativa dos peptídeos que irão diferir por 2Da (YE et al., 2009).

\section{Interatômica}

A interatômica destina-se ao estudo das interações entre proteínas sendo, portanto, fundamental para a compreensão do seu papel biológico. Os estudos que visam a caracterizar em larga escala proteínas que interagem podem ser realizados in silico (DROIT et al., 2005), utilizando ferramentas de predição computacionais (baseadas em domínios ou sítios evolutivamente conservados), in vitro (MONTI et al., 2009), com sistemas cromatográficos, ou in vivo (SUTER et al., 2008), por meio dos sistemas de híbridos. As estratégias in vitro para detecção de interações proteicas dependem da redução da complexidade de proteínas presentes na amostra. A cromatografia de afinidade é utilizada com esse objetivo. Para estudos em larga escala, podem ser 
empregados os microarranjos de proteínas ; ou então a purificação por afinidade em tandem (TAP) e os híbridos de levedura (POPESCU et al., 2007), os quais são os dois sistemas mais utilizados.

O TAP consiste na expressão de proteínasalvo fusionadas a etiquetas introduzidas geneticamente para promover a identificação dos híbridos. As proteínas-alvo fusionadas passam por uma matriz que contém um ligante específico para a etiqueta e são posteriormente eluídas da matrix pela ação de uma enzima com afinidade à outra porção da etiqueta. Os híbridos de levedura também envolvem a manipulação genética das leveduras para detecção de proteínas em larga escala que interagem no ambiente nuclear. No sistema two-hybrid system, duas culturas haploides de leveduras são utilizadas na construção de duas bibliotecas de cDNA. Em uma biblioteca, o vetor possui a sequência de um domínio de ligação ao DNA de um fator de transcrição fusionada à sequência-alvo (da amostra); na outra biblioteca, o vetor possui a sequência do fator de transcrição propriamente dito fusionada à sequência-alvo. Esse fator de transcrição é capaz de promover a transcrição de um gene repórter somente quando ligado ao domínio de ligação ao DNA. Assim, quando as duas culturas haploides são cruzadas, será observada a expressão do gene repórter somente nas células diploides em que as sequênciasalvo codificam para proteínas que interagem na célula, o que causa a aproximação do domínio de ligação ao DNA e do fator de transcrição no promotor do gene repórter. Depois de identificadas as células, DNA plasmidial é sequenciado para identificação das proteínas (CAUSIER, 2004).

Aplicações da proteômica na área vegetal

A produção de géis 2D tornou-se rotina na proteômica vegetal para estudar a expressão de centenas de genes, produzindo mapas proteicos correspondentes a diferentes genótipos, estádios de desenvolvimento e condições estressantes. Recentemente, o mapa proteico de raízes da leguminosa Lupinus albus foi caracterizado para identificar proteínas envolvidas na tolerância dessas plantas a substratos pobres em fósforo e também na capacidade fitorremediadora que esta leguminosa apresenta com o acúmulo de metais pesados (TIAN et al., 2009).

Os spots resolvidos nos géis 2D podem ser considerados marcadores genéticos ou fisiológicos, sendo úteis no acesso à variabilidade genética, bem como no estabelecimento de distâncias genéticas e relações filogenéticas entre linhagens, espécies e gêneros (THIELLEMENT et al., 2002). Em um estudo conduzido com linhas diplóides de Triticum sp., Secale sp. e Hordeum sp., foram estimadas as distâncias genéticas e suas relações filogenéticas entre as espécies com base no número de spots comuns e não comuns em géis 2D (ZIVY et al., 1995). A aplicabilidade da abordagem utilizada foi também evidenciada por meio da concordância dos resultados obtidos com aqueles oriundos da taxonomia clássica.

A produção de perfis proteicos na comparação de indivíduos com características de interesse contrastantes em espécies agronômicas envolvendo embriões (FUKUDA et al.,2003), endospermas (KOMATSU et al. 1993), raízes (ZHONG et al., 1997), cultura de células e folhas (SHEN et al.,2002) contribuem cada vez mais para o estudo funcional de proteínas envolvidas na germinação, no enchimento e na maturação de grãos e no desenvolvimento tardio ou precoce de grãos (HAJDUCH et al., 2005; DAI et al., 2007).

Em geral, a aplicação da proteômica no melhoramento genético de plantas pode se iniciar com a detecção de proteínas responsivas aos efeitos bióticos ou abióticos. Estudos na área de estresses abióticos, como seca, temperatura (SULE et al., 2004) e salinidade (DANI et al., 2005), e estresses bióticos, como doenças (KONISHI et al., 2001) e pragas, podem empregar a análise de proteínas diferencialmente expressas, com o intuito principal de fornecer base à descoberta de novos marcadores moleculares. Muitas dessas proteínas podem revelar funções consistentes com a resposta ao estresse. O próximo passo é verificar se o comportamento das proteínas cosegrega com a característica de interesse ou com um QTL (locos de caracteres quantitativos), permitindo a integração de genes de interesse em programas de melhoramento genético assistido por marcadores moleculares ou ainda em programas que incluem a transformação genética (TOUZET et al., 1995; SALEKDEH \& KOMATSU, 2007). A identificação dos principais efetores envolvidos na resposta de plantas ao estresse de déficit hídrico, por exemplo, tem sido alvo de muitos trabalhos. As respostas fenotípicas ao estresse de seca são comuns às plantas tolerantes e sensíveis (XIAO et al., 2009), o que dificulta a seleção de indivíduos superiores. Nesse sentido, XIAO et al. (2009) utilizaram gel-2D e MS para identificar proteínas diferencialmente expressas entre plantas de Populus adaptadas e não adaptadas à condição de seca as quais podem funcionar como biomarcadores na seleção assistida.

Outra aplicação importante seria na avaliação das modificações da expressão de proteínas decorrentes de mutações (SANTONI et al., 1994) ou até mesmo do processo de transgenia (RUEBELT et al., 2006). A identificação das proteínas afetadas, nesses 
casos, pode fornecer valiosas informações sobre os processos bioquímicos que são alterados no metabolismo desses indivíduos, derivados tanto dos efeitos pleiotrópicos quanto dos decorrentes das perturbações genéticas propriamente ditas (GSTAIGER \& AEBERSOLD, 2009). Plantas selvagens, variedades e plantas geneticamente modificadas (GM) de batata foram avaliadas quanto aos possíveis efeitos não intencionais da modificação genética sobre o proteoma de fundo ou não alvo da transgenia (LEHESRANTA et al., 2005). Rigorosas análises têm sido adotadas quando se trata da segurança alimentar de alimentos transgênicos e nesse aspecto a análise de perfis proteicos tem sido sugerida como uma estratégia mais abrangente para avaliação da equivalência substancial entre organismos GM e seus equivalentes não modificados (LEHESRANTA et al., 2005), como realizado por CORPILLO et al. (2004), que compararam o proteoma de plântulas de tomates GM para resistência a vírus com tomates não modificados.

A proteômica tornou-se uma importante abordagem na biologia molecular de plantas, e sua integração com técnicas clássicas de melhoramento genético resultam em novas possibilidades a serem alcançadas no desenvolvimento de variedades de plantas mais resistentes e produtivas.

\section{CONCLUSÕES}

O surgimento da espectrometria de massas foi decisivo para o desenvolvimento da proteômica contemporânea possibilitando experimentos em larga escala. Diversas plataformas de análise rápida, direta e sensível são utilizadas, dentre elas, os géis 2D e o shotgun, que tornou as análises ainda mais dinâmicas. No entanto, apenas a geração de dados proteômicos não resolve por si só a complexidade dos sistemas biológicos. É necessária a integração de dados oriundos da proteômica com a genômica, transcritômica e metabolômica, o que não é uma tarefa trivial. A combinação desses dados requer parâmetros normalizadores, controle experimental rígido e uma visão ampla para associar resultados estatísticos aos mecanismos moleculares da atividade celular. Nesse sentido, o futuro da proteômica está certamente calçado no incremento das ferramentas de bioinformática e estatística, bem como no desenvolvimento estratégico e tecnológico. Assim, a proteômica surge para expandir a gama de informações biológicas, permitindo entender melhor aspectos fundamentais da biologia de plantas e podendo gerar no futuro um evidente impacto nas práticas agronômicas.

\section{REFERÊNCIAS}

AEBERSOLD, R.; GOODLETT, D.R. Mass spectrometry in proteomics. Chemical reviews, v.101, n.2, p.269-296, 2001. Disponível em: <http://pubs.acs.org/doi/abs/10.1021/cr990076h>. Acesso em: 21 out. 2009. doi: 10.1021/cr990076h.

BLOM, N. et al. Prediction of post-translational glycosylation and phosphorylation of proteins from the amino acid sequence. Proteomics, v.4, n.6, p.1633-1649, 2004. Disponível em: <http:/ /www3.interscience.wiley.com/journal/108562767/abstract>. Acesso em: 21 out. 2009. doi: 10.1002/pmic.200300771.

CANTIN, G.T.; YATES, J.R. Strategies for shotgun identification of post-translational modifications by mass spectrometry. Journal of chromatography A, v.1053, n.1-2, p.7-14, 2004. Disponível em: < http://www.sciencedirect.com/science?_ob>. Acesso em: 11 jan. 2010. doi:10.1016/j.chroma.2004.06.046.

CAUSIER, B. Studying the interactome with the yeast twohybrid system and mass spectrometry. Mass spectrometry reviews, v.23, p.350-367, 2004. Disponível em: <http:// naturalsystems.uchicago.edu/evolgenome/Causier-Rev-04.pdf $>$. Acesso em: 11 jan. 2010. doi: 10.1002/mas.10080.

CORPILLO, D. et al. Proteomics as a tool to improve investigation of substantial equivalence in genetically modified organisms: the case of a virus-resistant tomato. Proteomics, v.4, p.193-200, 2004. Disponível em: <http://www.ncbi.nlm.nih.gov/pubmed/ 14730681>. Acesso em: 11 jan. 2010. doi:10.1002/ pmic. 200300540.

DAI, S. et al. Proteomic identification of differentially expressed proteins associated with pollen germination and tube growth reveals characteristics of germinated Oryza sativa pollen. Molecullar Cell Proteomics, v.6, p.207-230, 2007. Disponível em: <http://www.mcponline.org/cgi/content/ abstract/6/2/207>. Acesso em: 21 out. 2009. doi:10.1074/ mcp.M600146-MCP200

DANI, V. et al. Changes in the tobacco leaf apoplast proteome in response to salt stress. Proteomics, v.5, p.737-745, 2005. Disponível em: <http://www3.interscience.wiley.com/journal/ 109882227/abstract?CRETRY $=1 \&$ SRETRY $=0>$. Acesso em: 11 jan. 2010. doi: 10.1002/pmic.200401119.

DROIT, A. et al. Experimental and bioinformatic approaches for interrogating protein-protein interactions to determine protein function. Journal of Molecular Endocrinology, v.34, n.2, p.263-280, 2005. Disponível em: <http:// jme.endocrinology-journals.org/cgi/content/abstract/34/2/263>. Acesso em: 21 out. 2009. doi: 10.1677/jme.1.01693.

FUKUDA, M. et al. Assessing matrix assisted laser desorption/ ionization-time of flight-mass spectrometry as a means of rapid embryo protein identification in rice. Electrophoresis, v.24, p.1319-1329, 2003. Disponível em: <http:// www3.interscience.wiley.com/journal/104525696/abstract>. Acesso em: 21 out. 2009. doi: 10.1002/elps.200390168.

GSTAIGER, M.; AEBERSOLD, R. Applying mass spectrometrybased proteomics to genetics, genomics and network biology. Nature Reviews, v.10, p.617-627, 2009. Disponível em: <http://www.nature.com/nrg/journal/v10/n9/abs/nrg2633.html>. Acesso em: 21 out. 2009. doi:10.1038/nrg2633. 
HAJDUCH, M. et al. A systematic proteomic study of seedfilling in soybean: establishment of high-resolution twodimensional reference maps, expression profiles, and an interactive proteome database. Plant physiology, v.137, p.1397-1419, 2005. Disponível em: <http:// www.ncbi.nlm.nih.gov/pmc/articles/PMC1088330/>. Acesso em: 21 out. 2009. doi: 10.1104/pp.104.056614.

KOMATSU, S. et al. A rice protein library: a data-file of rice proteins separated by two-dimensional electrophoresis. Theoretical and applied genetics, v.86, p.935, 1993. Disponível em: <http://www.springerlink.com/content/ t48r664484082518/>. Acesso em: 21 out. 2009. doi: 10.1007/ BF00211044.

KONISHI, H. et al. A proteomics approach towards understanding blast fungus infection of rice grown under different levels of nitrogen fertilization. Proteomics, v.1, p.1162-1171, 2001. Disponível em: <http://www3.interscience.wiley.com/ journal/ 85512183/abstract>. Acesso em: 21 out. 2009. doi: $10.1002 / 1615-9861$ ( 200109 ) $1: 9<1162$ : : A I D PROT1162>3.0.CO;2-S.

LEHESRANTA, S.J. et al. Comparison of tuber proteomes of potato varieties, Landraces, and genetically modified lines. Plant Physiology, v.138, p.1690-1699, 2005. Disponível em: <http://www.plantphysiol.org/cgi/content/ abstract/138/3/1690>. Acesso em: 21 out. 2009. doi: 10.1104/ pp.105.060152.

LÓPEZ, J.L. et al. A proteomic approach to the study of the marine mussels Mytilus edulis and M. galloprovincialis. Marine biology, v.141, n.2, p.217-223, 2002. Disponível em: <http:/ /www.springerlink.com/content/e17axl55k89lh3tv/>. Acesso em: 21 out. 2009. doi: 10.1007/s00227-002-0827-4.

MANN, M.; JENSEN, O.N. Proteomic analysis of posttranslational modifications. Nature biotechnology, v.21, p.255-261, 2003. Disponível em: <http://www.nature.com/ nbt/journal/v21/n3/abs/nbt0303-255.html>. Acesso em: 21 out. 2009. doi:10.1038/nbt0303-255.

MATTICK, J.S. Challenging the dogma: the hidden layer of non-protein-coding RNAs in complex organisms. BioEssays, v.25, p.930-939, 2003. Disponível em: <http:// www3.interscience.wiley.com/journal/105056528/abstract $>$. Acesso em: 21 out. 2009. doi: 10.1002/bies.10332 .

MOTOYAMA, A.; YATES III, J.R. Multidimensional LC separations in shotgun proteomics. Analytical chemistry, v.80, n.19, p.7187-7193, 2008. Disponível em: <http:// pubs.acs.org/doi/abs/10.1021/ac8013669>. Acesso em: 21 out. 2009. doi: 10.1021/ac8013669.

MONTI, M. et al. Puzzle of protein complexes in vivo: present and future challenge for functional proteomics. Expert Review of Proteomics, v.6, n.2, p.159-169, 2009. Disponível em: <http://www.ingentaconnect.com/content/ftd/epr/2009/06/ 002>. Acesso em: 11 jan. 2010. doi:10.1586/epr.09.7.

NESATY, V.J.; SUTER, M.J.F. Analysis of environmental stress response on the proteome level. Mass spectrometry reviews, v.27, p.556-574, 2008. Disponível em: <http:// www3.interscience.wiley.com/journal/119877130/abstract $>$. Acesso em: 21 out. 2009. doi: 10.1002/mas.20177.
PENNINGTON, S.R.; DUNN. M.J. Proteomics: from protein sequence to function. New York: Springer-Verlag e BIOS scientific Plubishers, 2001. 1v.

POPESCU, S.C. et al. Differential binding of calmodulin-related proteins to their targets revealed through high-density Arabidopsis protein microarrays. Proceedings of the national academy of sciences of the United States of America, v.104, p.4730-4735, 2007. Disponível em: <http:/ /www.pnas.org/content/104/11/4730>. Acesso em: 11 jan. 2010. doi: 10.1073/pnas.0611615104.

RUEBELT, M.C. et al. Application of two-dimensional gel electrophoresis to interrogate alterations in the proteome of gentically modified crops. 3. Assessing unintended effects. Journal of Agricultural and Food Chemistry, v.54, n.6, p.2169-2177, 2006. Disponível em: <http:// www.ncbi.nlm.nih.gov/pubmed/16536592>. Acesso em: 11 jan. 2010. doi: 10.1021/jf0523566.

SALEKDEH, G.H.; KOMATSU, S. Crop proteomics: aim at sustainable agriculture of tomorrow. Proteomics, v.7, n.16, p.29762996, 2007. Disponível em: <http://www3.interscience.wiley.com/ journal/114294121/abstract>. Acesso em: 11 jan. 2010. doi: 10.1002/pmic.200700181.

SANTONI V, et al. Use of two-dimensional protein-pattern analysis for the characterization of Arabidopsis thaliana mutants. Planta, v.192, p.557-566, 1994. Disponível em: <http://www.springerlink.com/content/t70736nm21gw6wg7/>. Acesso em: 11 jan. 2010. doi: 10.1007/BF00203594.

SCHMIDT, C.; URLAUB, H. iTRAQ-labeling of in-gel digested proteins for relative quantification. Methods in Molecular Biology, v.564, p.207-226, 2009. Disponível em: <http:// www.ncbi.nlm.nih.gov/pubmed/19544025>. Acesso em: jan. 2010. doi: 10.1007/978-1-60761-157-8_12.

SEO, J.; LEE, K.J. Post-translational modifications and their biological functions: proteomic analysis and systematic approaches. Journal of biochemistry and molecular biology, v.37, n.1, p.35-44. Disponível em: <http:// www.jbmb.or.kr/fulltext/jbmb/view.php?vol=37\&page=35 $>$. Acesso em: 21 out. 2009.

SHEN, S. et al. A proteomic analysis of leaf sheaths from rice. Journal of biochemistry, v.132, p.613-620, 2002. Disponível em: <http://jb.oxfordjournals.org/cgi/reprint/132/4/613>. Acesso em: 21 out. 2009.

SULE, A. et al. Proteomic analysis of small heat shock protein isoforms in barley shoots. Phytochemistry, v.65, p.18531863, 2004. Disponível em: Acesso em: 21 out. 2009. doi: 10.1016/j.phytochem.2004.03.030.

SUTER, B. et al. Two-hybrid technologies in proteomics research. Current Opinion on Biotechnology, v.19, n.4, p.316-23, 2008. Disponível em: <http://www.ncbi.nlm.nih.gov/ pubmed/15276443>. Acesso em: 11 jan. 2010. doi: 10.1016/ j.copbio.2008.06.005.

TIAN, L. et al. Transcript and proteomic analysis of developing white lupin (Lupinus albus L.) roots. BMC Plant Biology, v.9, n.1, p.1-14, 2009. Disponível em: <http://www.ncbi.nlm.nih.gov/ pmc/articles/PMC2630931/pdf/1471-2229-9-1.pdf>. Acesso em: 11 jan. 2010. doi:10.1186/1471-2229-9-1. 
TYERS, M.; MANN, M. From genomics to proteomics. Nature, v.422, n.6928, p.193-197, 2003. Disponível em: <http://www.nature.com/nature/journal/v422/n6928/full/ nature01510.html>. Acesso em: 11 jan 2010. doi:10.1038/ nature 01510 .

THIELLEMENT, H. et al. Combining proteomic and genetic studies in plants. Chromatography B Analytical Technologies in Biomedical Life Sciences, v.782, n.1-2, p.137-149, 2002. Disponível em: <http://www.ncbi.nlm.nih.gov/pubmed/12458003>. Acesso em: 11 jan. 2010. doi:10.1016/S1570-0232(02)00553-6.

TOUZET, P. et al. Characterizing allelic proteins for genome mapping in maize. Electrophoresis, v.16, p.1289-1294, 1995. Disponível em: <http://www.ncbi.nlm.nih.gov/pubmed/7498178>. Acesso em: 11 jan 2010. doi: 10.1002/elps.11501601211.

TWYMAN, R.M. Strategies for protein identification. In: Principles of proteomics. York, UK. BIOS Scientific, 2004. Cap.3, p.49-65.

VENER, A.V. et al. Mass spectrometric resolution of reversible protein phosphorylation in photosynthetic membranes of Arabidopsis thaliana. Journal of biological chemistry, v.276, p.6959-6966, 2001. Disponível em: <http://www.jbc.org/ content/276/10/6959.full $>$. Acesso em: 11 jan. 2010. doi: 10.1074/jbc.M009394200.

XIAO, X. et al. Physiological and proteomic responses of two contrasting Populus cathayana populations to drought stress. Physiologia Platarum, v.136, p.150-168, 2009. Disponível em: <http://www3.interscience.wiley.com/journal/122200048/ > . Acesso em: 11 jan. 2010. doi: 10.1111/j.13993054.2009.01222.x.

WASHBURN, M.P. et al. Large-scale analysis of the yeast proteome by multidimensional protein identification technology. Nature biotechnology, v.19, p.242-247, 2001. 2009. Disponível em: <http://www.nature.com/nbt/journal/v19/ n3/full/nbt0301_242.html>. Acesso em: 11 jan. 2010. doi:10.1038/85686.

WILKINS, M.R. et al. Current challenges and future applications for protein maps and posttranslational vector maps in proteome projects. Electrophoresis, v.17, p.830-838, 1996. Disponível em: <http://www3.interscience.wiley.com/journal/110470660/ abstract>. Acesso em: 11 jan. 2010. doi: 10.1002/elps.1150170504.

YE, X. et al. 180 stable isotope labeling in MS-based proteomics. Briefings in Functional Genomics \& Proteomics. v.8, n.2, p.136-144, 2009. Disponível em: <http:/ /bfgp.oxfordjournals.org/cgi/content/abstract/eln055>. Acesso em: 21 out. 2009. doi:10.1093/bfgp/eln055.

YI, E.C.; GOODLETT, D.R. Quantitative protein profile comparisons using the isotope-coded affinity tag method. Current Protocols in Protein Science, Sup.34, unit 23.2, 2003. Disponível em: <http://www.ncbi.nlm.nih.gov/pubmed/ 18429263>. Acesso em: 11 jan. 2010. doi: 10.1002/ 0471140864.ps2302s34.

ZHONG, B. et al. Screening of rice genes from a cDNA catalog based on the sequence data-file of proteins separated by two-dimensional electrophoresis. Breeding science, v.47, p.245-251, 1997. Disponível em: <http://rms1.agsearch.agropedia.affrc.go.jp/contents/ JASI/pdf/society/56-0501.pdf $>$. Acesso em: 11 jan. 2010. doi: 10.1023/A:1026377931210.

ZIVY, M. et al. Distance indices in a comparison between the A, D, I and R genomes of the Triticeae tribe. Electrophoresis, v.16, p.1295-1300, 1995. Disponível em: <http:// www3.interscience.wiley.com/journal/110464113/abstract>. Acesso em: 11 jan. 2010. doi: 10.1002/elps.11501601212. 